\title{
Effect of Changes in Plasma Levels of Free Fatty Acids on Plasma Glucagon, Insulin, and Grow th Hormone in Man
}

\author{
Brendan H. Hicks, Charles I. Taylor, Satish K. Vii, Sumer Pek, Ralph F. Knopf, \\ John C. Floyd, Jr., and Stefan S. Fajans
}

\begin{abstract}
A regulatory role of acute changes in plasma concentration of free fatty acids on glucagon secretion has been suggested. We have studied the effect of such changes on plasma levels of glucagon, insulin, and growth hormone in man. Basal plasma levels of immunoreactive glucagon (IRG) were only slightly raised in 11 healthy subjects when the mean concentration of free fatty acids (FFA) was depressed to levels as low as $0.315 \pm 0.043$ (SEM) $\mathrm{mM}$ by infusion of nicotinic acid. Basal levels were increased modestly when the mean FFA level was elevated to $3.027 \pm 0.184$ $\mathrm{mM}$ by infusion of a triglyceride emulsion (Intralipid) with heparin. The plasma IRG response to intravenous arginine was unaffected by high or low levels of plasma
\end{abstract}

FFA. These findings contrasted with the effects upon plasma levels of immunoreactive insulin (IRI) and growth hormone (IGH). During elevation of F.:A levels, the mean basal level of plasma IRI increased by $100 \%$, and the IRI response to arginine increased by $\mathbf{5 0} \%$. Concomitantly, basal IGH levels and the plasma IGH response to arginine were suppressed markedly by elevation of FFA levels. The results of these studies do not offer support for a significant role of variation in plasma level of FFA as a regulator of acute changes in plasma IRG in man. An influence of changing levels of FFA on insulin secretion was found, and an effect on levels of growth hormone was confirmed.

$\mathbf{M}$

ETABOLIC SUBSTRATES such as glucose, amino acids, and free fatty acids (FFA) have important regulatory effects on a variety of hormones that influence the transfer of these substrates to or from energy stores. Rising plasma levels of glucose stimulate secretion of insulin and suppress secretion of glucagon and growth hormone. Opposite effects occur when plasma glucose levels are falling or hypoglycemia is induced. Rising levels of certain amino

From the Department of Internal Medicine (Division of Endocrinology and Metabolism and the Metabolism Research Unit), The University of Michigan, Ann Arbor, Mich.

Received for publication October 25, 1976.

Supported in part by USPHS grants AM-02244 and TI-AM05001, National Institute of Arthritis and Metabolic Diseases, by USPHS Grant SP 11 GM 15559, National Institute of General Medical Sciences, National Institutes of Health, and by Grants from the Upjohn Company, Kalamazoo, Mich., and the Pfizer Company, New York, N.Y.

Brendan H. Hicks, M.D.: Clinical Tutor and Consultant Physician, Dept. of Medicine, Guy's Hospital Medical School, London; supported by a Fogarty International Fellowship, NIH. Charles I. Taylor, M.D.: Clinical Instructor, Wayne State University, Detroit, Mich. Satish K. Vij, M.D.: Clinical Assistant Professor of Medicine, Loyola University, Maywood, Ill. Sumer Pek, M.D.: Associate Professor of Internal Medicine; Ralph F. Knopf, M.D.: Professor of Internal Medicine, John C. Floyd, Jr., M.D.: Professor of Internal Medicine; Stefan S. Fajans, M.D.: Professor of Internal Medicine, Division of Endocrinology and Metabolism and the Metabolism Research Unit. University of Michigan Medical School. Ann Arbor, Mich.

Presented before the 34th Annual Meeting, American Diabetes Association, Atlanta. Georgia, June 14-16, 1974 (Diabetes 23 [Suppl 1]:343, 1974).

Reprint requests should be addressed to Dr. Stefan S. Fajans, C7204, University Hospital, Ann Arbor, Mich. 48109.

(c) 1977 by Grune \& Stratton, Inc. ISSN 0026-0495. 
acids evoke increased secretion of insulin, glucagon, and growth hormone. In a number of reports it has been suggested that in man raised FFA levels enhance insulin ${ }^{1-8}$ and suppress growth hormone secretion, ${ }^{9-13}$ but in many of these reports the concomitant changes in plasma glucose concentration have made it impossible to identify an independent role of FFA. Three reports of the effects of changes in lipid levels on plasma glucagon levels in man have recently appeared. Gerich et al. reported ${ }^{14}$ that elevated plasma FFA levels were associated with decreases in basal plasma glucagon and in the glucagon response to arginine, and that depressed plasma FFA was associated with an increase in basal plasma glucagon but no change in the response to arginine. These findings were interpreted as showing that alterations in plasma FFA within the physiologic range may have a significant effect on glucagon secretion in man, and they seemed to extend results obtained in animals in vivo and in vitro. ${ }^{15-18}$ On the other hand, the report of Andrews et al. ${ }^{19}$ suggested only a minor role of lipids in the control of glucagon secretion, and that of Tiengo et al. ${ }^{20}$ included no relationship between FFA levels and glucagon secretion in normal subjects. In the present studies, conducted before publication of those reports, we examined the effect of changing levels of FFA on glucagon, insulin, and growth hormone levels in experiments performed in random order in a group of healthy subjects.

\section{MATERIALS AND METHODS}

Subjects. Eleven healthy male college students who had normal oral glucose tolerance tests were volunteers in a regular weckly rescarch program. They were 19-26 yr old, and their weights were $88 \%-109 \%$ of "desirable weight" (Metropolitan Life Insurance Company). Consent to these studies was on the basis of full information, with the approval of the Human Use Committee.

Procedures. During the 3 days preceding each experiment subjects avoided major deviations from their regular normal diet, then fasted and avoided medications and drugs for at least $12 \mathrm{hr}$ before the experiment commenced at 8:00 a.m. At the start of each experiment subjects were quizzed concerning strict adherence to these rules (hence the cancellation of one experiment in the saline-arginine series). A basal observation period of $30 \mathrm{~min}$ was followed by a 90 -min intravenous infusion designed to achieve high, low, or normal FFA levels; during the last 30 min of this infusion a second infusion of either isotonic saline or arginine hydrochloride was added. Plasma concentrations of substrates and hormones were measured during these periods, and during a further $90 \mathrm{~min}$.

\section{Protocols}

Five protocols were used:

1. Saline-arginine. First infusion: $0.9 \%$ saline, $405 \mathrm{ml}$ in $90 \mathrm{~min}$; second infusion: $100 \mathrm{mg} / \mathrm{ml}$ L-arginine hydrochloride (Cutter Laboratories), $4.9 \mathrm{ml} / \mathrm{kg}$ body weight (maximum $360 \mathrm{ml}, 36 \mathrm{~g}$ ) in $30 \mathrm{~min}$ ( 10 of the 11 subjects).

2. Nicotinic acid-arginine. First infusion: nicotinic acid (Eli Lilly), $1 \mathrm{mg} / \mathrm{kg}$ body weight in $20 \mathrm{ml}$ saline in $1 \mathrm{~min}$, then remainder of $200 \mathrm{mg}$ in $405 \mathrm{ml}$ saline in $89 \mathrm{~min}$; second infusion: arginine, as above (all subjects).

3. Intralipid-heparin-arginine. First infusion: Intralipid-heparin, $405 \mathrm{ml}$ in $90 \mathrm{~min}$; second infusion: arginine, as above (all subjects). The Intralipid-heparin solution consisted of $405 \mathrm{ml}$ of Intralipid ( $10 \%$ soy bean oil emulsion) (Cutter Laboratories), to which was added beef lung heparin (Eli Lilly), 40 units $/ \mathrm{kg}$ body weight.

4. Intralipid-heparin-saline. First infusion: Intralipid with heparin as above; second infusion: $0.9 \%$ saline, $4.9 \mathrm{ml} / \mathrm{kg}$ body weight (maximum $360 \mathrm{ml}$ ) in $30 \mathrm{~min}$ (all subjects).

These four protocols were used in the subjects in a randomized sequence, to minimize any bias.

5. Intralipid-low heparin-arginine. First infusion: Intralipid containing heparin, 200 units, $405 \mathrm{ml}$ in $90 \mathrm{~min}$; second infusion: arginine, as above ( 3 of the 11 subjects). 


\section{Determinations}

Blood samples were put into cold heparinized and (for triglyceride estimations) plain glass tubes, placed immediately in ice, centrifuged at $4^{\circ} \mathrm{C}$ within the hour, and rapidly deep frozen. Quality control studies confirmed that if these procedures were followed no significant change in the apparent concentrations, including those of immunoreactive glucagon, occurred between the time of collection and that of estimation. Measurements were made at intervals as shown in the figures or indicated in the text. Plasma glucose was estimated by an automated glucose oxidase method, ${ }^{21}$ plasma FFA by the technique of Dole and Meinertz, ${ }^{22}$ and serum triglycerides by a modified method of Van Handel and Zilversmit. ${ }^{23}$ Radioimmunoassays of glucagon, growth hormone, and insulin were of the double antibody type based on the method of Morgan and Lazarow. ${ }^{24}$

Immunoreactive glucagon (IRG) in plasma was determined using barbital-saline buffer, $0.1 \mathrm{M}$, $\mathrm{pH} 8.6$, containing $2.5 \mathrm{~g}$ /liter bovine serum albumin, crystalline beef-pork glucagon (Eli Lilly, lot 258-234B-167-1) as standard, and a rabbit anti-bovine-porcine-glucagon serum, G9-I. Antiserum G9-I, which reacts with the carboxyl terminal of the glucagon molecule, does not react with gastric inhibitory polypeptide, secretin, somatostatin, or threonine-phenylalanine-threonineserine tetrapeptide, nor with gastrin, insulin, or proinsulin. The affinity of the antiserum to the glucagonlike compounds present in a purified extract of porcine intestinal mucosa ("MUC-101," Novo Research Institute, Copenhagen, Denmark) is $2 \%-5 \%$ of its affinity to pancreatic glucagon.

All incubation tubes contained two proteinase inhibitors to minimize the degradation of glucagon: aprotinin (Trasylol, FBA) $1000 \mathrm{kIU} /$ tube, and benzamidine hydrochloride hydrate (Aldrich Chemicals) $0.01 \mathrm{M}$. The average sensitivity in 14 assays was $3.4 \mathrm{pg} /$ tube. The intraassay variation was $4.1 \%$, and the interassay variation was $14 \%$. Binding of hormones to their antibodies was not affected by Intralipid, palmitic acid, nicotinic acid, or heparin at plasma concentrations of the order reached or presumed to have been reached during these studies.

Statistical anatyses. Comparisons were evaluated by the two-tailed Student's $t$ test for paired and/or unpaired data. The glucagon data were also analyzed by considering values reexpressed as a percentage of or deviation from the average of the first three samples $(-90$ to $-60 \mathrm{~min})$, or deviation from the level at $0 \mathrm{~min}$. All values are presented as the mean $\pm \mathrm{SEM}$.

\section{RESULTS}

\section{Plasma FFA and Serum Triglyceride}

The infusion of isotonic saline was not associated with any significant change in plasma FFA level (Fig. 1). At time $0 \mathrm{~min}$, when the arginine infusions commenced, the mean level was $0.592 \pm 0.072 \mathrm{mM}$. During nicotinic acid infusion the 0 -min level was $0.315 \pm 0.043 \mathrm{mM}$ (compared with saline infusions, $p<$ 0.005 ), while during the Intralipid-heparin infusion it was $3.027 \pm 0.184 \mathrm{~m} M$ (compared with saline infusions, $p<0.001$ ). These respectively low and high levels of plasma FFA persisted until and for some minutes after the infusions ceased at $+30 \mathrm{~min}$. The FFA concentrations were low between 30 and $60 \mathrm{~min}$ during the saline-arginine study too, e.g., $0.383 \pm 0.054 \mathrm{~m} M$ at $60 \mathrm{~min}$.

Serum triglyceride concentrations were measured in 30 of the 46 experiments. There were no significant changes from the respective starting levels of $168 \pm 16$ and $153 \pm 13 \mathrm{mg} / \mathrm{dl}$ during saline or nicotinic acid infusions. During the Intralipid-heparin (40 units/ $\mathrm{kg}$ ) infusion, when arginine was the second infusion mean serum triglyceride level peaked at $0 \mathrm{~min}$ at $526 \pm 107 \mathrm{mg} / \mathrm{dl}$; when saline was the second infusion the level peaked $30 \mathrm{~min}$ later at $629 \pm 100 \mathrm{mg} / \mathrm{dl}$. During two Intralipid-low-heparin infusions serum triglyceride concentrations were slightly higher than in the high-heparin experiments; the mean FFA level did not exceed $1.195 \pm 0.174 \mathrm{~m} M$. 


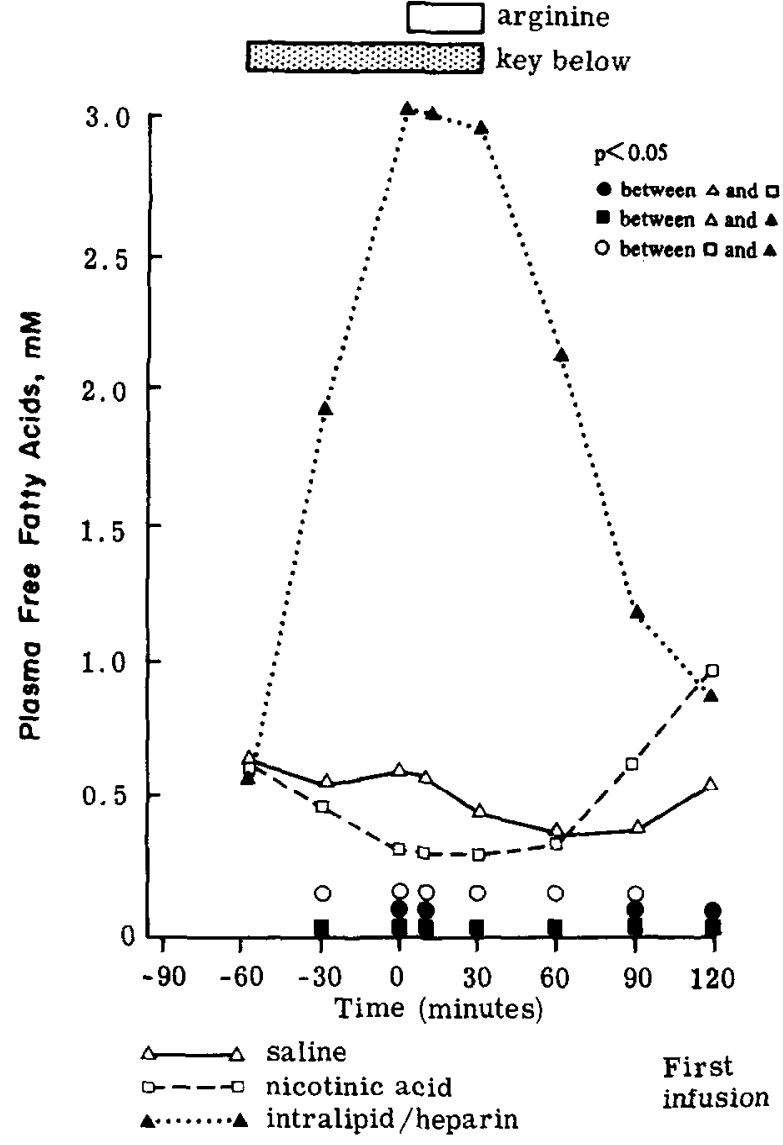

Fig. 1. Effects on mean plasma levels of FFA of introvenous infusions of saline, nicotinic acid, or Intralipid-heparin before and during infusions of arginine.

\section{Plasma Glucose}

Figure 2 illustrates that plasma glucose concentrations changed little before $0 \mathrm{~min}$ and rose during arginine infusion. During and $10 \mathrm{~min}$ after the arginine infusion plasma glucose was significantly lower when nicotinic acid was infused than when saline or Intralipid-heparin was infused.

\section{Plasma Immunoreactive Glucagon}

The basal levels of plasma IRG before infusions commenced were similar for all protocols and remained stable during saline infusion. During infusions of Intralipid-heparin and of nicotinic acid there were mild mean elevations before the commencement of arginine, reaching $109 \pm 23$ and $95 \pm 35 \mathrm{pg} / \mathrm{ml}$, respectively, with return to basal level by $0 \mathrm{~min}$ in the case of nicotinic acid infusions (Fig. 3). A slight upward trend continued in the absence of arginine in studies employing Intralipid-heparin and saline, the peak at $40 \mathrm{~min}$ then being recorded as $139 \pm 43 \mathrm{pg} / \mathrm{ml}$ (Fig. 4). However, these curves, at specific time points or as the areas of the increment over the initial basal level, did not differ from one another significantly. The incremental areas $(\mathrm{pg} \cdot \mathrm{min} / \mathrm{ml}$, mean $\pm \mathrm{SEM}$ ) from -60 to $0 \mathrm{~min}$ were for saline-arginine, $-52.8 \pm 454$, nicotinic acid-arginine, $1248 \pm 456(t=0.882)$, and Intralipid-heparin-arginine, $6677 \pm 453 \mathrm{pg} / \mathrm{ml}$. 
The plasma IRG response to arginine was generally similar during saline, nicotinic acid, and Intralipid-heparin infusions (Fig. 3). Only at 7 and $30 \mathrm{~min}$ of the Intralipid-heparin-arginine study were the plasma IRG levels statistically significantly higher than those during the saline-arginine experiments, but not when the data were expressed as increments over the 0 -min levels. No statistically significant differences in the plasma IRG responses were evident when IRG areas during the period $0-120 \mathrm{~min}$ were compared. The $0-120$-min incremental areas $(\mathrm{pg} \cdot \mathrm{min} / \mathrm{ml}$, mean $\pm \mathrm{SEM})$ during and following the arginine infusions were, for saline-arginine, $7740 \pm 1850$, nicotinic acid-arginine, $14,460 \pm 3,045(t=0.804)$, Intralipid-heparin-arginine, $6969 \pm 2064 \mathrm{pg} / \mathrm{ml}$. Thus the mean plasma IRG responses to arginine were very similar at high, low, and normal plasma levels of FFA.

When in three subjects the plasma triglyceride levels were raised to over 500 $\mathrm{mg} / \mathrm{dl}$ by infusion of Intralipid-low-heparin (not illustrated), the glucagon response to arginine was again similar to that following saline.

\section{Plasma Immunoreactive Insulin}

During saline and nicotinic acid infusions plasma immunoreactive insulin (IRI) levels did not change significantly by 0 min (Fig. 5), whereas during Intra-

Fig. 2. Effect on mean plasma levels of glucose of intravenous infusions of saline, nicotinic acid, or Intralipid-heparin (normal, low, and high FFA conditions, respectively) before and during infusions of arginine.

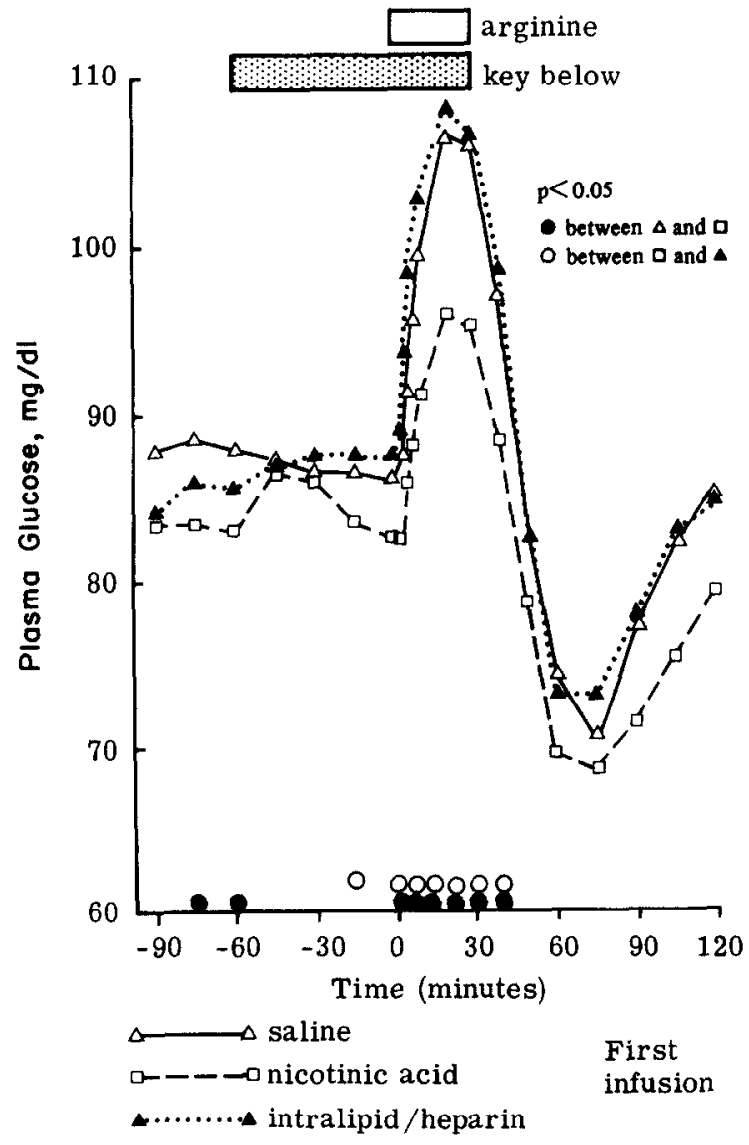




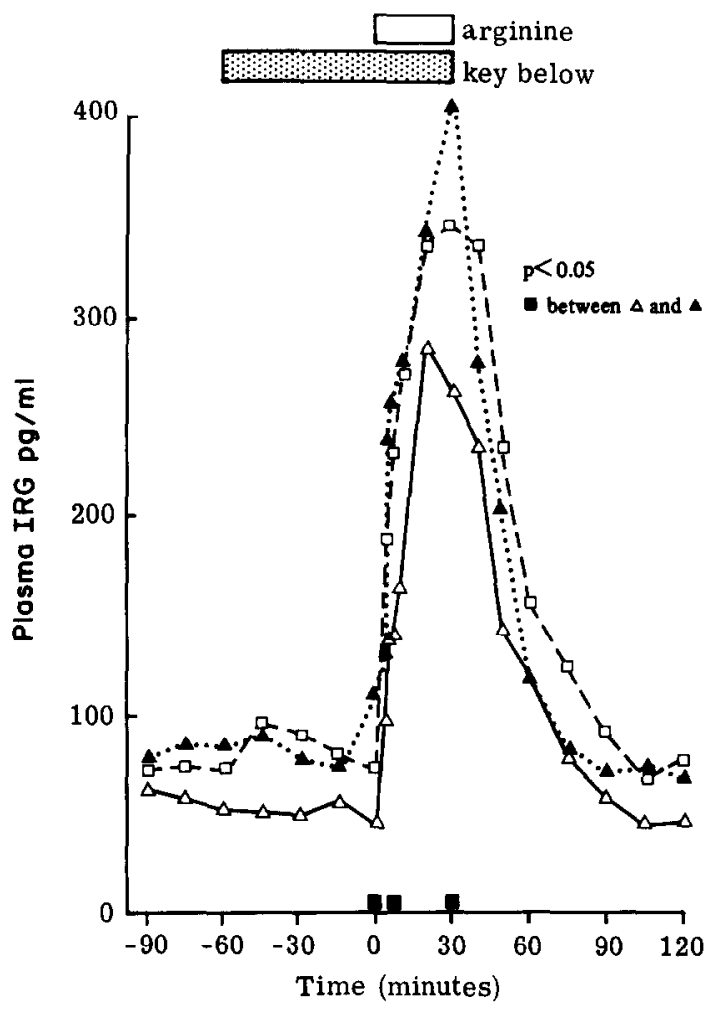

$\leadsto$ saline

- $-\rightarrow$ nicotinic acid

^....... intralipid/heparin
First infusion

Fig. 3. Effects on mean plasma levels of immunoreactive glucagon of in. travenous infusions of saline, nicotinic acid, or Intralipid-heparin (normal, low, and high FFA conditions, respectively) before and during infusions of arginine.

Fig. 4. Effects of intravenous infusions of Intralipid-heparin before and during infusions of isotonic saline on mean plasma levels of IRG, IGH, IRI, glucose, and FFA.

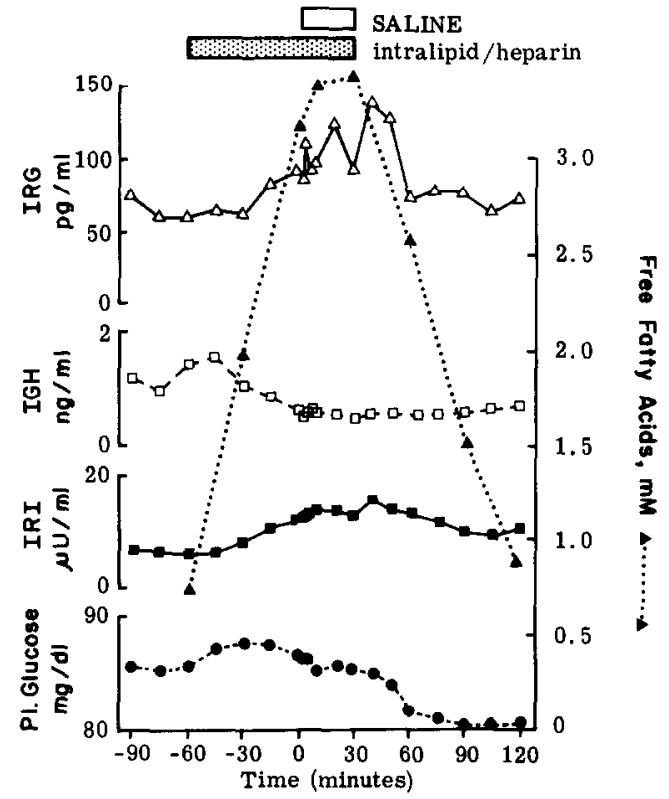


Fig. 5. Effect on mean plasma levels of immunoreactive insulin of intravenous infusions of saline, nicotinic acid, or Intralipid-heparin (normal, low, and high FFA condifions, respectively) before and during infusions of arginine.

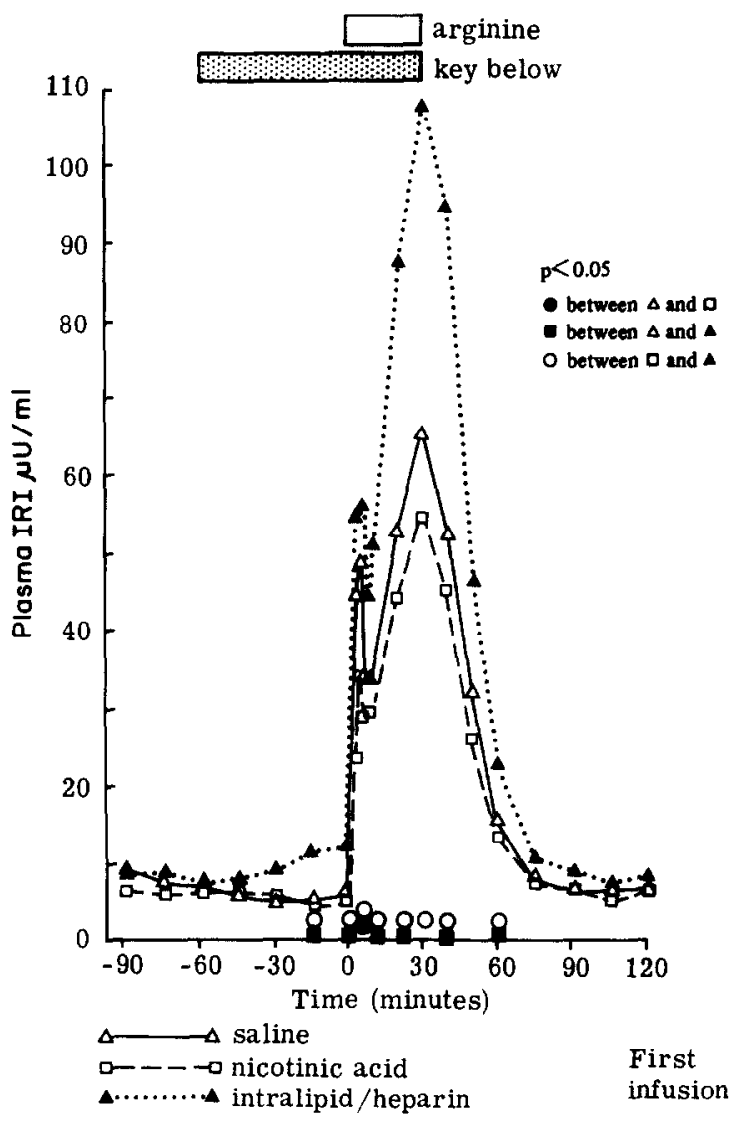

lipid-heparin infusion the mean IRI concentration rose from a basal level of $8 \pm 2$ to $12 \pm 2 \mu$ units $/ \mathrm{ml}$ at $0 \mathrm{~min}$, significantly higher than the corresponding level for saline infusion, $6 \pm 1 \mu$ units $/ \mathrm{ml}(p<0.005)$. In studies in which Intralipid was given together with saline, plasma IRI continued its rise to reach a peak level of $15 \pm 2 \mu$ units $/ \mathrm{ml}$ at $40 \mathrm{~min}$ (Fig. 4).

The IRI response to arginine was lower when nicotinic acid was infused as compared to control, but only at $3-\min (24 \pm 5$ versus $45 \pm 8 \mu$ units $/ \mathrm{ml}, p<$ $0.05)$ and $5-\mathrm{min}(35 \pm 4$ versus $49 \pm 5 \mu$ units $/ \mathrm{ml}, p<0.05$ ) time points (Fig. 5). The overall response, however, was not significantly reduced as judged by the area of increased IRI concentration under the curve, which was only about $15 \%$ less than the control value. During Intralipid-heparin infusion the IRI response to arginine was much augmented, peak concentration at $30 \mathrm{~min}$ reaching a mean of $107 \pm 17$ as compared to the control of $66 \pm 11 \mu \mathrm{units} / \mathrm{ml}, p<0.02$. The mean rise in IRI concentration between 0 and $30 \mathrm{~min}$, and during the arginine infusion, was $95 \pm 17$ with Intralipid as opposed to $61 \pm 12 \mu$ units/ml without $(\mathrm{p}<0.05)$, indicating that this augmentation was more than a simple elevation of starting level. Similar augmentation of the IRI response was also seen in three experiments of the low-heparin type (not illustrated), in which mean FFA levels rose only to $1.195 \mathrm{~m} M$. 


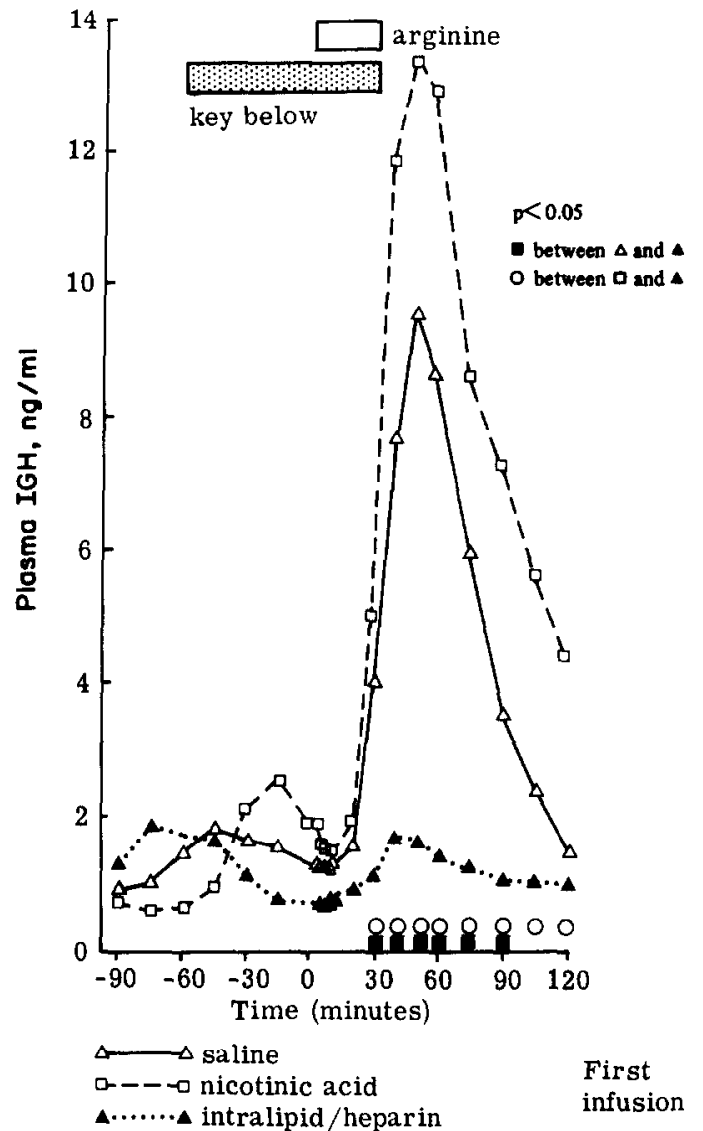

Fig. 6. Effects on mean plasma levels of immunoreactive growth hormone of intravenous infusions of saline, nicotinic acid, or Intralipid-heparin (normal, low, and high FFA conditions, respectively) before and during infusions of arginine.

\section{Changes in Plasma Immunoreactive Growth Hormone}

During the infusion of nicotinic acid, plasma levels of immunoreactive growth hormone (IGH) rose from a mean value of $0.7 \pm 0.2 \mathrm{ng} / \mathrm{ml}$ at $-60 \mathrm{~min}$ to $2.5 \pm 1.4$ at $-15 \mathrm{~min}$ and $1.9 \pm 0.8 \mathrm{ng} / \mathrm{ml}$ at $0 \mathrm{~min}$ (Fig. 6). In contrast, Intralipid-heparin was associated with a downward drift of $\mathrm{IGH}$ to $0.7 \pm 0.2$ $\mathrm{ng} / \mathrm{ml}$ at $0 \mathrm{~min}$, and, if an infusion of saline was then added (Fig. 4), by a further downward drift to a nadir of $0.5 \pm 0.1 \mathrm{ng} / \mathrm{ml}$ at $30 \mathrm{~min}$. During this Intralipid-heparin-saline experiment mean plasma IGH levels between 0 and 105 min were significantly lower than the mean basal value $(p<0.05)$, and the mean area under the growth hormone curves between -60 and 0 min for all Intralipid-heparin experiments was significantly less, at $15.1 \pm 4.1 \mathrm{ng} \cdot \mathrm{min} / \mathrm{ml}$, than the same area when only saline was infused, $28.5 \pm 6.9 \mathrm{ng} \cdot \mathrm{min} / \mathrm{ml}(p<$ 0.03).

During the period from -60 to $60 \mathrm{~min}$ within which Intralipid-heparin and saline were infused (Fig. 4), the growth hormone area was less than one-half the area under the curve between -60 and $0 \mathrm{~min}$ in studies in which saline alone was infused $(-46.6 \pm 17$ versus $57.1 \pm 7.1 \mathrm{ng} \cdot \mathrm{min} / \mathrm{ml}$, respectively; $p<0.03)$.

During saline and nicotinic acid experiments arginine caused the expected rise in $\mathrm{IGH}$ levels, the respective mean values at $50 \mathrm{~min}$ being $9.5 \pm 2.9$ and $13.3 \pm 2.9 \mathrm{ng} / \mathrm{ml}$ (Fig. 6). During these studies the means of the individual peak 
Table 1. Peak Levels of Plasma Growth Hormone in Response to Arginine Under Protocols 1-3

\begin{tabular}{|c|c|c|c|c|c|c|}
\hline \multirow[b]{2}{*}{ Subject } & \multirow{2}{*}{$\begin{array}{c}\text { SA } \\
\text { Peak } \\
\text { Level }\end{array}$} & \multicolumn{2}{|c|}{ NAA } & \multicolumn{3}{|c|}{ IHA } \\
\hline & & $\begin{array}{l}\text { Peak } \\
\text { Level }\end{array}$ & $\begin{array}{c}\text { Difference } \\
\text { From SA }\end{array}$ & $\begin{array}{l}\text { Peak } \\
\text { Level }\end{array}$ & $\begin{array}{l}\text { Difference } \\
\text { From SA }\end{array}$ & $\begin{array}{l}\text { Difference } \\
\text { From NAA }\end{array}$ \\
\hline 1 & 17.5 & 11.4 & -6.1 & 4.6 & -12.9 & -6.8 \\
\hline 2 & 7.3 & 2.9 & -4.4 & 0.9 & -6.4 & -2.0 \\
\hline 3 & 21.2 & 12.4 & -8.8 & 0.7 & -20.5 & -11.7 \\
\hline 4 & 19.4 & 17.6 & -1.8 & 5.5 & -13.9 & -12.1 \\
\hline 5 & 10.0 & 20.4 & 10.4 & 4.4 & -5.6 & -16.0 \\
\hline 6 & - & 16.8 & - & 3.9 & - & -12.9 \\
\hline 7 & 1.9 & 2.4 & 0.5 & 0.2 & -1.7 & -2.2 \\
\hline 8 & 2.2 & 14.3 & 12.1 & 1.2 & -1.0 & -13.1 \\
\hline 9 & 0.4 & 34.4 & 34.0 & 0.9 & 0.5 & -33.5 \\
\hline 10 & 3.1 & 4.7 & 1.6 & 0.6 & -2.5 & -4.1 \\
\hline 11 & 22.2 & 25.5 & 3.3 & 0.5 & -21.7 & -25.0 \\
\hline Mean time & 54 & 49 & & 51 & & \\
\hline of peak (min) & $( \pm 4)$ & $( \pm 2)$ & & $( \pm 4)$ & & \\
\hline Meon & 10.52 & 14.80 & 4.08 & 2.13 & -8.57 & 12.67 \\
\hline \pm SEM & \pm 2.69 & \pm 2.95 & \pm 3.93 & \pm 0.61 & \pm 2.57 & \pm 2.91 \\
\hline \multicolumn{7}{|c|}{ Significance of difference } \\
\hline Unpaired, $p$ & & & NS & & $<0.02$ & $<0.001$ \\
\hline Paired, $p$ & & & NS & & $<0.01$ & $<0.005$ \\
\hline
\end{tabular}

Individual and mean peak levels of plasma $1 G H(\mathrm{ng} / \mathrm{ml})$ in response to arginine infusions during saline, nicotinic acid, or Intralipid-heparin infusions (normal, low, and high FFA conditions, respectively) (SA, NAA, and IHA, respectively). NS, not significant.

levels were $10.5 \pm 2.7$ and $14.8 \pm 4.1 \mathrm{ng} / \mathrm{ml}$, respectively (Table 1 ), and the mean area under the curve between 0 and $120 \mathrm{~min}(0-\mathrm{min}$ value used as baseline) was greater during nicotinic acid infusion $(597 \pm 218 \mathrm{ng} \cdot \mathrm{min} / \mathrm{ml})$ than the control (saline-arginine) $(388 \pm 144 \mathrm{ng} \cdot \mathrm{min} / \mathrm{ml})$, but these differences were not statistically significant.

When Intralipid-heparin was infused, the IGH response to arginine was virtually abolished, the suppression (as compared to levels during saline-arginine) being seen in nine of ten subjects (Table 1), and it was statistically significant at 30-90 min (Fig. 6). The area under the curve was also significantly less, $55 \pm 22$ versus $388 \pm 144 \mathrm{ng} \cdot \mathrm{min} / \mathrm{ml}(p<0.05)$. In the three studies employing low doses of heparin (not illustrated) no effect of lipid upon IGH levels could be detected.

\section{DISCUSSION}

The findings in relation to growth hormone (Fig. 6) confirm and extend those of Blackard et al. ${ }^{10}$ who reported that an almost complete suppression of IGH response to arginine occurred in the presence of elevated FFA levels and that neither elevation of triglycerides nor the injection of heparin had this effect. Others have recorded suppression by FFA of the sleep-induced IGH peak ${ }^{12}$ and the IGH response to beefsteak, ${ }^{11}$ but not of exercise-induced growth hormone secretion. ${ }^{25}$ The Intralipid-heparin-saline experiments also demonstrated that basal levels of IGH are suppressed when FFA levels are elevated. This effect on basal growth hormone secretion has been previously reported only in baboons. ${ }^{26}$ 
During infusion of nicotinic acid IGH levels gradually rose, and under these conditions arginine provoked an IGH response $50 \%$ greater than during control experiments. Although the finding was not statistically significant, it should be viewed in the light of the report of Quabbe et al. ${ }^{13}$ They demonstrated a basal IGH increase during and after nicotinic acid while FFA levels were low. They also showed that this increase was blocked by lipid-heparin infusion but not by glucose, indicating the potency of the FFA effect and providing reassurance that the increases in IGH are unlikcly to be merc responses to stress induced by nicotinic acid. The two subjects of ours who suffered transient discomfort with nicotinic acid showed the lowest IGH levels overall.

During Intralipid-heparin infusions basal levels of plasma IRI increased to a statistically significant degree (Figs. 4 and 5). Many previous studies in man of basal insulin have failed to show any change following orally ${ }^{2,7.8}$ or intravenously ${ }^{1,7,27,28}$ administered lipid or heparin. ${ }^{14}$ Only Pi-Sunyer et al. ${ }^{5}$ found modest rises in insulin levels, in subjects who had ingested meals of mediumchain triglycerides or corn oil, but FFA levels were not measured. In our experiments, during the basal period small $(2-3 \mathrm{mg} / \mathrm{dl})$ and transient increases in plasma glucose (Figs. 2 and 4) and small rises in plasma IRG (Figs. 3 and 4) occurred, but the size and timing of these changes were such that they were probably not an important factor in the insulin response.

A marked augmentation of the plasma IRI response to infused arginine was seen (Fig. 5) during Intralipid-heparin studies. During Intralipid-low-heparin experiments, the smaller increases in FFA (mean maximal level of $1.195 \mathrm{mM}$ ) were also accompanied by augmentation of arginine-induced insulin release. In another study, when mean plasma FFA was raised to about $0.70 \mathrm{~m} M$ by heparin injection alone, no augmentation of arginine-induced insulin release was observed. ${ }^{14}$ In the presence of high FFA concentrations the insulin response to intravenous glucose has been reported by some to be unaffected, ${ }^{27}$ by some to be increased in the presence of abnormally high glucose values, ${ }^{2,8}$ and by others to be potentiated cven in the presence of lower glucose levels. ${ }^{4}$

The mechanisms by which basal and arginine-induced insulin release are enhanced during infusions of Intralipid and heparin are not known, but they are unlikely to include effects of ketones, ${ }^{29-32}$ triglycerides, ${ }^{2,28}$ or glycerol. ${ }^{4,33}$ In the dog ${ }^{34}$ direct infusion of long-chain FFA into the pancreatic artery, achieving local concentrations between 0.6 and $0.8 \mathrm{~m} M$, resulted in increased insulin secretion; thus an effect of FFA on the $\beta$-cell is likely to exist.

We found little evidence that depression of FFA levels could be a factor in the control of insulin secretion. Only at the 3- and 5-min time points of the arginine infusions was plasma IRI significantly lower in the presence of nicotinic acid, and at this time the plasma glucose was about $5 \mathrm{mg} / \mathrm{dl}$ lower. Balasse and Ooms ${ }^{8}$ did show a depressant effect of nicotinic acid injections on plasma insulin responses to glucose, glucagon, and tolbutamide (arginine was not employed). They interpreted their data as showing also that lowering plasma FFA resulted in a significant fall in basal plasma insulin, but the "suppressed" levels in the low-FFA study were close to basal levels in other experiments in the study. Apart from decreases in plasma FFA similar to those reported here, the experimental conditions were different: $100 \mathrm{mg}$ of nicotinic acid was injected 
every $15 \mathrm{~min}$ over a period of $3 \mathrm{hr}$, a total of $1200 \mathrm{mg}$, and those studied were obese, being $122 \%-183 \%$ of "ideal weight."

We have not been able to demonstrate any definite influence of elevated or depressed plasma FFA levels on plasma IRG. We did note modest increases in plasma IRG when plasma FFA was elevated to supraphysiologic levels by Intralipid-heparin infusion. In this connection the effects of the small amounts of glycerol, $2.5 \%$, and egg yolk phospholipid, $1.2 \%$, contained in Intralipid are not known, but an effect of the FFA cannot be excluded.

When Gerich et al. ${ }^{14}$ raised FFA levels to $0.712 \mathrm{~m} M$ by injecting 5000 units heparin intravenously every $15 \mathrm{~min}$, they noted decreases in basal levels of plasma glucagon; a mean basal level of $122 \mathrm{pg} / \mathrm{ml}$ fell to $59 \mathrm{pg} / \mathrm{ml}$. Andrews et al. ${ }^{19}$ reported suppression of the mean basal glucagon level of $128 \mathrm{pg} / \mathrm{ml}$ to $82 \mathrm{pg} / \mathrm{ml}$ when FFA levels were elevated by ingestion of Lipomul (Upjohn) (containing $60 \mathrm{~g}$ corn oil) and injection of 5000 units heparin, or by infusing Intralipid-heparin. It may be relevant that initial "basal" levels were somewhat high in these studies. Although both groups reported suppression of basal plasma glucagon when plasma FFA was elevated, only Gerich et al. ${ }^{14}$ found that the glucagon response to arginine was reduced. As reported herein, Blackard et al. ${ }^{19}$ found no suppression of the plasma glucagon response to arginine.

In contrast to our findings, when plasma levels of FFA were lowered by two 200 -mg injections ${ }^{14}$ or a 30 -min $400-\mathrm{mg}_{\text {infusion }}{ }^{19}$ of nicotinic acid, basal levels of glucagon increased. Blackard et al., ${ }^{19}$ who reported an increase from 73 to $137 \mathrm{pg} / \mathrm{ml}$, concluded that the increases in basal plasma glucagon noted during nicotinic acid infusion were induced by stress or some related factor; the same risc in glucagon was seen when they infused nicotinic acid and Intralipidheparin simultaneously and thereby prevented the fall in FFA concentration but not the symptoms related to nicotinic acid. We (Fig. 6) and others ${ }^{13}$ have noted early during nicotinic acid administration an occasional increase in plasma IGH only. Perhaps we could demonstrate only a modest transient increase in plasma IRG during administration of nicotinic acid because we administered a total of only $200 \mathrm{mg}$ nicotinic acid over a period of $120 \mathrm{~min}$, whereas others administered $400 \mathrm{mg}$ during $15^{14}$ and $30^{19} \mathrm{~min}$. In neither of the other acute studies ${ }^{14,19}$ nor in this study was the plasma IRG response to arginine influenced by nicotinic acid or low FFA levels.

In a controlled study of patients with hypertriglyceridemia before and after 2-4 mo treatment with clofibrate, Tiengo et al. ${ }^{20}$ found no correlation between FFA and glucagon fasting levels or response to arginine, but they did find an increased glucagon response in the patients as compared to controls that was further increased by treatment with clofibrate.

It must be stated that in in vivo ${ }^{15,16}$ and in vitro ${ }^{17,18}$ animal experiments the weight of evidence, although not extensive, would support the existence of an inhibitory influence of FFA at the $\alpha$-cell. However, it is entirely possible that the balance of substrates and hormonal influences operating in the various animal species are quite different from those in man. On the basis of differing protocols and findings, the evidence in man that plasma levels of FFA may exert physiologic influence upon glucagon secretion is equivocal. Thus in just one of six sets of experiments in this study and in two other acute studies was there an 
effect upon arginine-stimulated release of glucagon. The fact that alteration of plasma FFA within the physiologic range had a significant effect on basal levels of plasma glucagon in their experiments led Gerich et al. ${ }^{14}$ to conclude that changes in plasma FFA may exert a physiologic influence over human pancreatic $\alpha$-cell function, but the results of our studies do not suggest that variations in plasma levels of FFA play a significant role in the regulation of glucagon secretion in man. Andrews et al. ${ }^{19}$ showed that supraphysiologic plasma levcls of FFA, although suppressing basal glucagon, did not suppress arginineor hypoglycemia-induced glucagon secretion in man. They and Tiengo et al. ${ }^{20}$ also concluded that if FFA have a physiologic role in regulation of glucagon secretion, then it must be a minor one.

\section{REFERENCES}

1. Felber JP, Vannotti A: Effects of fat infusion on glucose tolerance and plasma insulin levels. Med Exp 10:153-156, 1964

2. Schalch DS, Kipnis DM: Abnormalities in carbohydrate tolerance associated with elevated plasma non-esterified fatty acids. J Clin Invest 44:2010-2020, 1965

3. Balasse E, Ooms HA: Effet d'une élévation aiguë du taux des acides gras libres (NEFA) sur la tolérance glucidique et la résponse insulinique à l'hyperglycémie chez l'homme normal. Rev Fr Clin Biol 13:62-67, 1968

4. Pelkonen R, Miettinen TA, Taskinen MR, et al: Effect of acute elevation of plasma glycerol, triglyceride and free fatty acid levels on glucose utilization and plasma insulin. Diabetes 17:76-82, 1968

5. Pi-Sunyer FX, Hashim SA, van Itallie TB: Insulin and ketone responses to ingestion of medium- and long-chain triglycerides in man. Diabetes 18:96-100, 1969

6. McCullough FS, Tzagournis M, Greenberger NJ, et al: Stimulation of insulin secretion by medium chain triglycerides in patients with cirrhosis. Gut 12:134-138, 1971

7. Carroll KF, Nestel PJ: Effect of longchain triglycerides on human insulin secretion. Diabetes 21:923-929, 1972

8. Balasse EO, Ooms HA: Role of plasma free fatty acids in the control of insulin secretion in man. Diabetologia 9:145-151, 1973

9. Tsushima T, Matsuzaki F, Irie M: Effect of heparin administration on plasma growth hormone concentrations. Proc Soc Exp Biol Med 133:1084-1088, 1970

10. Blackard WG, Hull EW, Lopez-S A: Effect of lipids on growth hormone secretion in humans. J Clin Invest 50:1439-1443, 1971

11. Fineberg SE, Horland AA, Merimee TJ: Free fatty acid concentrations and growth hormone secretion in man. Metabolism 21:491498,1972
12. Lucke C, Adelman N, Glick SM: The effect of elevated free fatty acids (FFA) on the sleep-induced human growth hormone peak. J Clin Endocrinol Metab 35:407-412, 1972

13. Quabbe HJ, Bratzke HJ, Siegers U, et al: Studies on the relationship between plasma free fatty acids and growth hormone secretion in man. J Clin Invest 51:2388-2398, 1972

14. Gerich JE, Langlois M, Schneider V, et al: Effects of alterations of plasma free fatty acid levels on pancreatic glucagon secretion in man. J Clin Invest 53:1284-1289, 1974

15. Madison LL, Seyffert WA, Unger RH, et al: Effect of plasma free fatty acids on plasma glucagon and serum insulin concentrations. Metabolism 17:301-304, 1968

16. Luyckx $\wedge$ S, Lefebvre PJ: Arguments for a regulation of pancreatic glucagon secretion by circulating plasma free fatty acids. Proc Soc Exp Biol Mcd 133:524-528, 1970

17. Edwards JC, Taylor KW: Fatty acids and the release of glucagon from isolated guinea pig islets of Langerhans incubated in vitro. Biochim Biophys Acta 215:310-315, 1970

18. Luyckx AS, Massi-Benedetti F, Lefebvre PJ: Changes in insulin and glucagon secretion related to concentrations of metabolic substrates in the isolated perfused rat pancreas (manuscript in preparation), as quoted, in Lefebvre PJ, Unger RH (eds): Glucagon: Molecular Physiology, Clinical and Therapeutic Implications. Oxford, Pergamon, 1972, p 227

19. Andrews SS, Lopez-S A, Blackard WG: Effect of lipids on glucagon secretion in man. Metabolism 24:35-44, 1975

20. Tiengo A, Muggeo M, Assan R, et al: Glucagon secretion in primary endogenous hypertriglyceridemia before and after clofibrate treatment. Metabolism 24:901-914, 1975

21. Medzihradsky F, Dahlstrom PJ: A specific, low cost procedure for the automated de- 
termination of blood glucose. Univ Mich Med Ctr J 4:188-190, 1971

22. Dole VP, Meinertz H: Microdetermination of long chain fatty acids in plasma and tissues. J Biol Chem 235:2595-2599, 1960

23. Van Handel E, Zilversmit DM: Micromethod for the direct determination of serum triglycerides. J Lab Clin Med 50:152-157, 1957

24. Morgan CR, Lazarow A: Immunoassay of insulin: Two antibody system. Diabetes 12: 115-126, 1963

25. Hansen AAP: The effect of intravenous infusion of lipids on the exercise-induced serum growth hormone rise in normals and juvenile diabetes. Scand J Clin Lab Invest 28:207-212, 1971

26. Cryer PE, Coran AG, Keenan BS, et al: Cessation of growth hormone secretion associated with acute elevation of the serum free fatty acid concentration. Metabolism 21:867873,1972

27. Thorell J, Persson B, Sterkey G: Effect of fat infusion on plasma glucose, free fatty acid, glycerol and insulin lcvels during intravenous and oral glucose tolerance tests. Diabetologia 2:232, 1966 (Abstr)
28. Gibson T, Fuller JH, Grainger SL, et al: Intralipid triglyceride and oral glucose tolerance. Diabetologia 10:97-100, 1974

29. Fajans SS, Floyd JC Jr, Knopf RF, et al: A comparison of leucine and acetoacetateinduced hypoglycemia in man. J Clin Invest 43 : 2003-2008, 1964

30. Sauls HS: Effect of beta-hydroxybutyrate infusion and heparin-induced ketosis. Pediatr Res 1:220, 1967 (Abstr)

31. Balasse E, Ooms HA: Changes in the concentration of glucose, free fatty acids, insulin and ketone bodies in the blood during sodium beta-hydroxybutyrate infusions in man. Diabetologia 4:133-135, 1968

32. Senior B, Loriden B: Direct regulatory effect of ketones on lipolysis and on glucose concentration in man. Nature 219:83-84, 1968

33. Tamir J, Grant DB, Fosbrooke AS, et al: Effects of single load of MCT on serum lipid and insulin levels in man. J Lipid Res 9:661666,1968

34. Crespin SR, Greenough WB, Steinberg D: Stimulation of insulin secretion by infusion of long-chain free fatty acids. J Clin Invest 52: 1979-1984, 1973 